\title{
Protection without Discrimination: Pregnancy and Occupational Health Regulations
}

\begin{abstract}
Sven Ove-Hansson and Linda Schenk*
Occupational exposures of pregnant workers can give rise to foetal damage. Two major types of strategies against detrimental effects on the foetus are described: differentiated protection that reduces only the exposure of pregnant workers (or only of female workers) and unified protection that reduces the exposure of all workers to a level that is sufficiently low to protect against detrimental effects on the foetus. The former strategy is shown to be inefficient, as it does not provide the desired protection. Protection only of pregnant workers is insufficient since protection is needed early in pregnancy when it is not known, and in the case of substances that are accumulated in the woman's body even prior to conception. Protection of all women is also insufficient to protect the foetus since evidence indicates that preconception exposure of the father can also give rise to malformations. Furthermore, differentiated protection that requires more costly protective measures for women tends to aggravate the already prevalent discrimination of women on the labour market. It is therefore concluded that unified protection is the only efficient and non-discriminatory strategy against foetal damage.
\end{abstract}

\section{Introduction}

The first factory legislation in the 19th century protected only women and children, leaving the work conditions of men unregulated. The reason for this was ideological. Men were assumed to be able to take care of themselves. Women received (albeit insufficient) protection, not primarily due to biological differences but due to their dependent legal status. Today, health and safety legislation treats women and men equally in terms of the basic right to protection against workplace hazards. However, occupational health research has usually focused on male workers, and many of the more detailed regulations have been developed with a view to male workers as a norm. ${ }^{1}$ However, there is one area where the regulatory as well as the research focus has been on female workers, and that is reproductive toxicity caused by workplace exposures. Most women are pregnant during their working life. In pregnancy, risks to the foetus add to those that affect the woman herself. The focus of research and regulation has however not primarily been on the protection of women's health, but on the health of the foetus. ${ }^{2}$

Reproductive toxicity, and more specifically, developmental toxicity is a key issue in many of the presently ongoing discussions on how to regulate chemical risks. The identification and regulation of endocrine disrupting compounds is a high profile issue. These concerns are mainly directed at the foetus and the developing child, as it has been proposed that there are periods during development when the individual is extremely sensitive and that very low exposures during these periods cause severe and irreversible effects. ${ }^{3}$ The choice of an appropriate approach to developmental toxicity in quantitative hazard assessment has also surfaced as an area of con-

\footnotetext{
* Sven Ove Hansson is professor at the Department of Philosophy and History, Royal Institute of Technology, Stockholm. Linda Schenk is a researcher at the Department of Philosophy and History, Royal Institute of Technology, Stockholm. The authors would like to thank Bengt Sjögren at Karolinska Institutet for valuable comments on an earlier draft of this article.

1 Katherine Lippel and Karen Messing "A Gender Perspective on Work, Regulation and Their Effects on Women's Health and WellBeing." In Theo Nichols and David Walters (eds.) Safety or Profit (Amityville, New York : Baywood Publishing Company, 2013), at pp. 35-40.

2 Ibid. at pp. 34-35.

3 WHO UNEP State of the science of endocrine disrupting chemicals - 2012. Åke Bergman, Jerrold J. Heindel, Susan Jobling, Karen A. Kidd and R. Thomas Zoeller (eds.) (Geneva: United Nations Environment Programme and the World Health Organization, 2013), at pp. 10-11
} 
flict between the new European chemicals regulation REACH and existing EU workplace regulations. ${ }^{4}$

The protection of an adult worker from exposure that may be dangerous to the foetus is a special case of a more general problem, namely that of protecting sensitive groups from workplace hazards. There are two regulatory approaches to this situation, namely separate provisions for the sensitive group (differentiated protection) and a general level of protection that is sufficient for all identified groups (unified protection).

There is a sizable literature on the risk assessment of individual substances with potential reproductive and developmental toxicity. However, there is a lack of systematic and principled discussions on the basic risk management strategy for dealing with these risks, and in particular on the choice between differentiated and unified protection. It is the purpose of the present paper to contribute to filling this lacuna in the risk management literature and to propose a science-based strategy that protects the foetus against toxic occupational hazards without leading to discrimination of future parents on the workplace or on the labour market.

We are going to show that a unified strategy is in most cases superior to a differentiated strategy for regulating the employer's responsibility to protect workers' future children from hazards in the workplace. The argument is two-fold. First, a differentiated strategy fails to efficiently protect workers' prog-

4 See for instance the case of N-Methyl-2-pyrrolidone, where the restriction proposal under $\mathrm{REACH}$ specifically identified risks to the foetus of pregnant workers while provisions under workplace health legislations generally have focussed on respiratory irritation. This latter focus results in higher exposures being considered acceptable than what the restriction proposal identifies as needed to protect the foetus. http://echa.europa.eu/previous-consultations -on-restriction-proposals/-/substance-rev/1899/term (last accessed on 09 October 2015)

5 Jordi Julvez and Philippe Grandjean "Neurodevelopmental toxicity risks due to occupational exposure to industrial chemicals during pregnancy", 47 Industrial Health (2009) 459 et sqq.

6 Vilma R. Hunt, Work and the Health of Women. (Boca Raton: CRC Press, 1979), at p. 118.

7 J.M. Ratcliffe., P.R. McElhatton, and F.M. Sullivan, "Reproductive Toxicology", in Bryan Ballantyne, Timothy Marrs, and Paul Turne (eds.), General and Applied Toxicology, vol 2, (Basingstoke: Macmillan Press, 1993), at pp. 995 et sqq.

8 Julvez and Grandjean, supra note 5.

9 Strictly speaking, PCB is a group of substances rather than a substance, but it is usually treated as a single entity in assessments of occupational exposure.

10 Philippe Grandjean and Philip J. Landrigan "Neurobehavioural impact of developmental toxicity" 13 Lancet Neurology (2014), pp. 330 et sqq. eny. Second, a differentiated strategy may aggravate the already prevalent discrimination of women on the labour market. In the following sections we provide additional background on the issues at hand and then present our arguments in more detail. Section II provides an overview of workplace hazards that may harm the foetus. In Section III, some current regulatory approaches to protecting the foetus from harmful occupational exposures are described. In Section IV, the two major types of strategies for protection of sensitive groups are delineated, and a set of criteria for the choice between these strategies is presented. In Section V, these criteria are applied to developmental toxicants in the workplace, and in Section VI the conclusions of this article are summarized.

\section{Workplace Exposures - Foetus at Risk}

Relatively few epidemiological studies of occupational exposure during pregnancy have been reported, and most of the existing studies are based on small samples. Furthermore, most of these studies focus on two groups of substances: organic solvents and pesticides, in particular organophosphate insecticides. ${ }^{5}$ This focus is adequate due to the neurotoxic effects of these two groups of substances, but the lack of information on other substances is highly problematic. Studies in this area are hampered by the fact that effects on the foetus are much more difficult to detect than effects on the workers themselves, since larger groups of workers are needed to obtain a statistically sufficient number of pregnancies than a sufficient number of exposed workers. ${ }^{6,7}$ Julvez and Grandjean $^{8}$ noted that 201 individual industrial chemicals are known (from epidemiology or clinical experience) to be neurotoxic to humans but only 5 of them (arsenic, lead, methyl mercury, toluene and $\mathrm{PCB}^{9}$ ) are known to cause human neurodevelopmental toxicity. Since we have strong reasons to believe the foetus to be at least as sensitive to neurotoxic effects as the adult human, this difference probably depends on lack of knowledge rather than absence of hazard. Neurotoxic effects on the foetus can give rise to severe lifelong detriment to cognition. Observational studies have furthermore found exposure to some neurodevelopmental toxicants to be a risk factor for school failure as well as unemployment and criminality in adulthood. ${ }^{10}$ For instance, a US cohort 
study found that increased blood lead levels before birth and during early childhood were associated with higher rates of arrests for criminal offenses as young adults. ${ }^{11}$

There are several findings of developmental toxicity connected to solvent exposure during pregnancy, both occupational exposure and after use as intoxicants. Evidence from toluene sniffing during pregnancy shows that this substance can have serious negative effects on brain development. ${ }^{12}$ Furthermore, occupational exposure to perchloroethylene during pregnancy has been shown to substantially increase the risk of the child developing schizophrenia later in life. ${ }^{13}$ A meta-analysis confirmed that exposure of pregnant women to organic solvents is associated with increases in spontaneous abortions and major malformations (defined as potentially life threatening or involving a major cosmetic defect). ${ }^{14}$

In many countries, female agricultural workers are exposed to organophosphate insecticides on a massive scale. ${ }^{15}$ The children of female agricultural workers in California exposed to organophosphates had lower average mental development and higher behav-

11 John Paul Wright, Kim N. Dietrich, M. Douglas Ris, Richard W. Hornung, Stephanie D. Wessel, Bruce P. Lanphear, Mona Ho, Mary N. Rae "Association of Prenatal and Childhood Blood Lead Concentrations with Criminal Arrests in Early Adulthood" 5 PLoS Med (2008), pp. e101 et sqq. This prospective cohort study provides strong evidence of a correlation between early lead exposure and adult criminality. However, although controlling for several confounding factors, it is not to be considered as proof of a direct causal link between early lead exposure and adult criminality. Wright et al. also bring up the possibility that the higher arrest rate is due to lead exposure causing decreased intelligence, i.e. that higher lead exposure makes it more likely that a criminal offender will be arrested.

12 Philippe Grandjean and Philip J. Landrigan "Developmenta neurotoxicity of industrial chemicals", 368 Lancet (2006), pp. 2167 et sqq.

13 Mary C. Perrin, Mark G. Opler, Susan Harlap, Jill HarkavyFriedman, Karine Kleinhaus, Daniella Nahon, Shmuel Fennig, Ezra S. Susser, and Dolores Malaspina "Tetrachloroethylene exposure and risk of schizophrenia: offspring of dry cleaners in a population birth cohort, preliminary findings",90 Schizophrenia Research (2007), pp. 251 et sqq.

14 Kristen I. McMartin, Merry Chu, Ernest Kopecky, Thomas R. Einarson and Gideon Koren "Pregnancy outcomes following maternal organic solvent exposure: a meta-analysis of epidemiologic studies" 34 American Journal of Industrial Medicine (1998) pp. 288 et $s q q$.

15 Julvez and Grandjean, supra note 5.

16 Jessica G Young, Brenda Eskenazi, Eleanor A. Gladstone, Asa Bradman, Lesley Pedersen, Caroline Johnson, Dana B. Barr, Clement E. Furlong, and Nina T. Holland "Association between in utero organophosphate pesticide exposure and abnormal reflexes in neonates", 26 Neurotoxicology (2005), pp. 199 et sqq.

17 Brenda Eskenazi, Amy R. Marks, Asa Bradman, Kim Harley, Dana B. Barr, Caroline Johnson, Norma Morga, Nicholas P. Jewell ioural disorder frequency than unexposed controls, as measured with standard tests. ${ }^{16,17}$ Similarly, several studies have shown that children of pesticide-exposed women working in agriculture in Ecuador and Mexico score lower than non-exposed controls in terms of motor skills, communication and problem solving abilities, creativity, and visual acuity. ${ }^{18}$ In addition, a meta-analysis has shown a connection between maternal occupational exposure to pesticides and increased risk of childhood leukaemia. ${ }^{19}$

Acute exposures to carbon monoxide have been shown to cause foetal malformations and spontaneous abortions. ${ }^{20}$ More recent evidence also indicates that also subclinical carbon monoxide exposures may adversely affect foetal neurodevelopment. ${ }^{21}$ Maternal occupational exposure to anaesthetic gases increases the risk of spontaneous abortion. $^{22,23}$

The risk of malformations is greatest if the embryo/foetus is exposed during organogenesis (second to seventh week) or the early foetal period (eighth to fifteenth week). ${ }^{24,25,26}$ It is therefore often assumed that risk management measures should focus on ex-

"Organophosphate pesticide exposure and neurodevelopment in young Mexican-American children", 115 Environmental Health Perspectives (2007), pp. 792 et sqq.

18 Julvez and Grandjean, 2009, supra note 5.

19 Geneviève Van Maele-Fabry, Anne-Catherine Lantin, Perrine Hoet, and Dominique Lison "Childhood leukaemia and parental occupational exposure to pesticides: a systematic review and meta-analysis", 21 Cancer Causes Control (2010) pp. 787 et sqq.

20 Christine A. Norman and David M. Halton "Is carbon monoxide a workplace teratogen? A review and evaluation of the literature." 34 Annals of Occupational Hygiene (1990), pp. 335 et sqq.

21 Richard J. Levy "Carbon monoxide pollution and neurodevelopment: A public health concern" 49 Neurotoxicology and Teratology (2015), pp. 31 et sqq.

22 Jean-Francois Boivin "Risk of spontaneous abortion in women occupationally exposed to anaesthetic gases: a meta-analysis" 54 Occupational and Environmental Medicine (1997), pp. 541 et sqq.

23 A. Shirangi, L. Fritschi, and C.C. Holman "Maternal occupational exposures and risk of spontaneous abortion in veterinary practice", 65 Occupational and Environmental Medicine (2008), pp. 719 et sqq.

24 James L. Weeks, Barry S. Levy, and Gregory R. Wagner, Preventing Occupational Disease and Injury, (Washington D.C.: American Public Health Association, 1991.), at pp. 489 et sqq.

25 P. W. J. Peters and J. M. Garbis-Berkvens, "General Reproductive Toxicology." in Raymond J.M Niesink, John de Vries, and Mannfred A. Hollinger (eds.), Toxicology. Principles and Applications. (Boca Raton: CRC Press, 1996), at pp. 935 et sqq.

26 Pamela M. Williams and Stacy Fletcher "Health effects of prenatal radiation Exposure", 82 American Family Physician (2010), pp. 488 et sqq. 
posures of the mother during this period. However, exposure of the foetus can be delayed in relation to that of the mother if the substance is stored in her body. Heavy metals such as lead and cadmium accumulate in the body, and the same applies to persistent pesticides. Therefore all previous exposures of the mother to these substances, even exposures many years ago, may have negative effects. Furthermore, lipophilic substances such as organic solvents and some of their metabolites can be stored in the body for a considerable time. Logman and colleagues recommended that women who wish to have children should "minimize their exposure to organic solvents in the 3 months (or longer, depending on the kinetics of the particular solvent) prior to the planned conception date." ${ }^{27}$

Maternal exposure to ionizing radiation is known to be hazardous to the foetus. This applies to diagnostic and therapeutic exposures, and of course also to occupational exposures. The foetus is estimated to be about three times more sensitive to the carcinogenic effects of radiation than the population average. ${ }^{28}$ At higher levels of exposure, radiation may give rise to spontaneous abortion, growth restriction, and mental retardation. ${ }^{29}$

With the exception of radiation, little is known about the effects on the foetus of non-chemical working conditions. Most studies have found little or no negative impact on the foetus of standing, bending or lifting on the workplace, but the findings are in-

27 J Floris S Logman, Laurens E. de Vries, Michiel E.H. Hemels, Sohail Khattak, and Thomas R. Einarson "Paternal organic solvent exposure and adverse pregnancy outcomes: a meta-analysis", 47 American Journal of Industrial Medicine (2005), at p. 42.

28 ICRP The 2007 Recommendations of the International Commission on Radiological Protection, J. Valentin (ed.), Annals of the ICRP, Publication 103. (Oxford: Elsevier, 2007), at p. 57.

29 Williams and Fletcher 2010, supra note 26.

30 H.M. Salihu, , J. Myers, and E.M. August "Pregnancy in the workplace", 62 Occupational Medicine (2012),pp. 88 et sqq.

31 Gladys Friedler "Paternal exposures: Impact on reproductive and developmental outcome. An overview", 55 Pharmacology Biochemistry and Behavior (1996), pp. 691 et sqq.

32 Sylvaine Cordier "Evidence for a role of paternal exposures in developmental toxicity", 102 Basic \& Clinical Pharmacology \& Toxicology (2008), pp. 176 et sqq.

33 Tania A Desrosiers, Amy H Herring, Stuart K Shapira, Mariëtte Hooiveld, Tom J Luben, Michele L Herdt-Losavio, Shao Lin, Andrew F Olshan "Paternal occupation and birth defects: findings from the National Birth Defects Prevention Study" 69 Occupational and Environmental Medicine (2012), pp. 534 et sqq.

34 Diana Anderson, Thomas E Schmid, and Adolf Baumgartner, "Male-mediated developmental toxicity", 16 Asian Journal of Andrology (2014), pp. 81 et sqq. conclusive and some studies indicate that standing all day may possibly increase the likelihood of spontaneous abortion or preterm birth. ${ }^{30}$

The information summarized above concerns hazards to the foetus mediated through maternal exposure. However, for ionizing radiation and some substances, paternal exposure seems to have similar effects. ${ }^{31}, 32,33,{ }^{34}$ Exposure of fathers to organic solvents is associated with increased risk of central nervous system malformations, in particular neural tube defects including anencephaly (but apparently not spontaneous abortions). The same applies to paternal exposure to pesticides. ${ }^{35}, 36,37$ A recent study found that preconceptional paternal serum concentrations of several persistent organic pollutants were associated with differences in birth size among offspring. ${ }^{38}$ Genetic and epigenetic mechanisms as well as direct toxicity (through contamination of seminal fluid) have been proposed for male-mediated developmental toxicity. ${ }^{39,}{ }^{40}$ Little is known about mechanisms, required exposures and sensitive windows of exposure. Results from different epidemiological studies are often not comparable due to differences in the grouping of birth defects, and the results from comparable groups are not necessarily consistent. ${ }^{41}$ Furthermore, small sample sizes and poor or lacking exposure estimates in most available epidemiological studies hinder the quantitative assessment of dose-response relationships. ${ }^{42}$ Animal models may offer some guidance on causality and toxic doses. ${ }^{43}$

35 S.E Chia. and L.M. Shi "Review of recent epidemiological studies on paternal occupations and birth defects", 59 Occupational and Environmental Medicine (2002), pp. 149 et sqq.

36 Logman et al 2005, supra note 27.

37 Mohamed El-Helaly, Kamal Abdel-Elah, Ayman Haussein, and Hend Shalaby "Paternal occupational exposures and the risk of congenital malformations - a case-control study", 24 International Journal of Occupational Medicine and Environmental Health (2011), pp. 218 et sqq.

38 Candace A. Robledo, Edwina Yeung, Pauline Mendola, Rajeshwari Sundaram, Jose Maisog, Anne M. Sweeney, Dana Boyd Barr, and Germaine M. Buck Louis, "Preconception Maternal and Paternal Exposure to Persistent Organic Pollutants and Birth Size: The LIFE Study", 123 Environmental Health Perspectives (2015), pp. 88 et sqq.

39 Cordier, 2008, supra note 32.

40 Steven M. Schrader and Katherine L. Marlow "Assessing the reproductive health of men with occupational exposures", 16 Asian Journal of Andrology (2014), pp. 23 et sqq.

41 See e.g. discussion by Desrosiers et al., 2012, supra note 33.

42 Schrader and Marlow, 2014, supra note 40.

43 Anderson et al., 2014, supra note 34. 
However, animal studies are scarce, partly since regulatory testing strategies focus on female-mediated developmental toxicity. In regulatory risk assessment the practice has been to assume that germ cell mutagens act through a non-threshold mechanism, i.e. that no "safe" level of exposure exists. However, we still lack data to confirm or disconfirm the hypothesis that doses too low to cause toxicity in the male may still cause developmental toxicity in his offspring.

\section{Regulatory Approaches: A few European Examples}

Article 15 of the occupational health and safety framework directive ${ }^{44}$ states that "[p]articularly sensitive risk groups must be protected against the dangers which specifically affect them". In a daughter directive, the European Pregnant Workers Directive from 1992, specific provisions were introduced for workers who are pregnant, recently have given birth and/or are breastfeeding. ${ }^{45}$ The directive recognizes that pregnant workers "must be considered a specific risk group in many respects". When a woman has announced to the employer that she is pregnant, then the employer is required to perform a pregnancy risk assessment and based on that assessment make sure that the identified risks are avoided either by "temporarily adjusting the working conditions and/or the working hours of the worker concerned" or by moving her to another job. Specific attention in the risk assessment should be directed to certain groups of substances. A non-exhaustive list is given in Annex I of the directive. ${ }^{46}$ It includes categories such as carcinogens, mutagens, developmental toxicants, and substances with significant skin uptake, but it also specifically mentions carbon monoxide, antimitotic drugs, mercury and its derivatives. Lead and its derivatives are listed in Annex II, which outlines exposures and working conditions not allowed for pregnant or breastfeeding women.

The pregnant workers directive does not include provisions on pre-conception hazards, such as protecting workers' fertility or limiting the accumulated body burden of developmental toxicants.

Occupational exposure limits (OEL) are another regulatory measure for the protection of workers' health. These are numerical values that define a maximal concentration of a substance in workplace air, or sometimes in biological matrices. Depending on the standard-setter, OELs can be legally binding or be set as recommendations. The EU sets two kinds of OELs, binding OELs and indicative OELs. Binding ('pragmatic') OELs take socio-economic and technical factors into account, and all member states have to implement the value of the binding OEL, or a lower value, in national regulations. Indicative ('healthbased') OELs are stated to be based solely on the medical and toxicological evaluation of the substance. They are recommendations that member states have to take into account, but the national OELs may be either higher or lower.

To date there is only one biological OEL in the EU, that of inorganic lead and its compounds. ${ }^{47}$ This value is set to $70 \mu \mathrm{g}$ lead / $100 \mathrm{ml}$ blood, for the whole worker population. Here it can be noted that the EU expert group, the Scientific Committee on OELs (SCOEL), published in 2002 a recommendation of 30 $\mu \mathrm{g} / 100 \mathrm{ml}$, adding that this "is not seen as being entirely protective of the offspring of working women" and that the "exposure of fertile women to lead should therefore be minimised." ${ }^{48}$ In Sweden the EU biological OEL for lead has been incorporated into the provisions on medical surveillance at work. ${ }^{49}$ These provisions stipulate that female workers below the age of 50 years shall not have blood concentrations exceeding $1.2 \mathrm{\mu mol} \mathrm{lead/litre}(25 \mathrm{\mu g}$ lead/100 ml blood).

44 Council Directive 89/391/EEC on the introduction of measures to encourage improvements in the safety and health of workers at work OJ 1989 L 183/1.

45 Council Directive 92/85/EEC of 19 October 1992 on the introduction of measures to encourage improvements in the safety and health at work of pregnant workers and workers who have recently given birth or are breastfeeding (tenth individual Directive within the meaning of Article 16 (1) of Directive 89/391/EEC) OJ 1992 L 348/1.

46 Amended by Directive 2014/27/EU of the European Parliament and of the Council of 26 February 2014 amending Council Directives 92/58/EEC, 92/85/EEC, 94/33/EC and Directive 2004/37/EC of the European Parliament and of the Council in order to align them to Regulation (EC) No 1272/2008 on classification, labelling and packaging of substances and mixtures, OJ 2014 L 65/1.

47 Council directive 98/24/EC of 7 April 1998 on the protection of the health and safety of workers from the risks related to chemical agents at work fourteenth individual Directive within the meaning of Article 16(1) of Directive 9/391/EEC), OJ 1998 L 131/11.

48 Scientific Committee on Occupational Exposure Limits (SCOEL), Recommendation from the Scientific Committee on Occupational Exposure Limits for lead and its inorganic compounds. SCOEL/SUM/83, January 2002 (European Commission. DG Employment, Social Affairs \& Inclusion, 2002), at pp. 3 et sqq

49 Swedish Work Environment Authority, "AFS 2005:6 Medicinska kontroller i arbetslivet," [Provisions 2005:6 on medical checks in working life] (Stockholm, Swedish Work Environment Authority, 2005), at pp. 6-8. 
For males or females at least 50 years old the limit is $2 \mu \mathrm{mol}$ lead / litre blood (41 $\mu \mathrm{g}$ lead / $100 \mathrm{ml}$ blood ). Certain exemptions from the surveillance obligations are also allowed in case the employee in question is a male or a female at least 50 years old. These stricter criteria for women in fertile age are explicitly justified with reference to the risk to future offspring. ${ }^{50}$

The EU OELs for inhalation exposure are not differentiated according to sensitive sub-groups, nor is there any specific notation connected to the EU OELs on pregnancy risks. The Scientific Committee on OELs states that "the objective of OEL setting is to prevent adverse health effects in occupationally exposed persons and/or their progeny". ${ }^{51}$ However, it is also emphasized that due to a general lack of data on reproductive toxicity, OELs may not protect sufficiently against such effects. Another approach to reproductive toxicity and OELs is taken by the German MAK-commission, which sets health-based and nonbinding OELs and includes a notation on the pregnancy risk group. ${ }^{52}$ There are four pregnancy risk groups:

Group A: Damage to the embryo or foetus in humans has been unequivocally demonstrated and is to be expected even when [OELs] are observed. Group B: According to currently available information damage to the embryo or foetus must be expected even when [OELs] are observed. The documentation indicates, when the Commission's assessment of the data makes it possible, which concentration would correspond to the classification in Pregnancy Risk Group C. Substances with this indication have the footnote 'prerequisite for Group C, see documentation'.

Group C: There is no reason to fear damage to the embryo or foetus when [OELs] are observed.

50 Ibid

51 Scientific Committee on Occupational Exposure Limits (SCOEL), Methodology for the Derivation of Occupational Exposure Limits. Key Documentation, version 7 June 2013. (European Commission. DG Employment, Social Affairs \& Inclusion, 2013), at p. 24

52 Deutsche Forschungsgemeinschaft, "2014 MAK and BAT values: Maximum Concentrations and Biological Tolerance Values at the Workplace", 2014, Available on the Internet at: http:// onlinelibrary.wiley.com/book/10.1002/9783527682027 (last accessed on 9 October 2015).

53 Ibid., at p 211

54 Sven Ove Hansson "Should we protect the most sensitive people?" 29 Journal of Radiological Protection (2009) pp. 211 et sqq.

55 Linda Schenk "Comparison of data used for setting occupational exposure limits", 16 International Journal of Occupational and Environmental Health (2010) pp. 253-254.
Group D: Either there are no data for an assessment of damage to the embryo or foetus or the currently available data are not sufficient for classification in one of the groups A-C. ${ }^{53}$

This approach is essentially differentiated, as OELs for substances with the A or B notation are not sufficient for the protection of pregnant workers although OELs for substances with notation $\mathrm{C}$ would correspond to a unified protection.

\section{Criteria for Regulatory Strategies}

As has been outlined in the previous section there are two major regulatory strategies for the protection of sensitive groups against workplace hazards. ${ }^{54}$ Differentiated protection operates through measures targeted at the sensitive persons, specifically reducing or eliminating their exposure. It can take the form of excluding them from certain occupations or environments or providing them with special protective equipment. The above-mentioned examples of specific provisions for pregnant workers, stricter medical surveillance of fertile females occupationally exposed to lead, and OEL notations on pregnancy risk belong to the strategy of differentiated protection.

Unified protection, in contrast, means that exposure limits and other regulations are the same for all individuals, but they are sufficiently strict to protect the members of the sensitive group(s). The EU indicative OELs are an example of unified protection from the perspective of reproductive and developmental toxicity, as according to SCOEL, they are aimed at protecting both exposed workers and their offspring. Another, substance specific, example is a decision by Australian health and safety authorities to adopt an occupational exposure limit for carbon tetrachloride (o.1 ppm) calculated to be low enough to protect alcoholics against the substance's hepatotoxic effects. These effects are much potentiated by alcohol consumption. In contrast, the US OSHA set a much higher exposure limit for this substance (10 ppm) that was not intended to protect against these combination effects. $^{55}$

Differentiated protection usually has economic advantages, as exposure reduction measures and medical surveillance can be costly to the employer. On the other hand, differentiated protection can have social disadvantages such as excluding parts of the pop- 
ulation from certain employments. The following six criteria have been proposed as a checklist for determining which of the two methods is appropriate ${ }^{56}$ :

1. The difference in risk: If the difference in risk is small between the sensitive group and the rest of the population, then differentiated protection will not be meaningful. Hence, having an exposure limit of 5 (in some unit) for one of the sexes and 6 for the other would in most cases be impracticable due to lack of precision in both measurements and abatement.

2. The costs of abatement: If it is inexpensive to reduce exposures, then there is little economic gain from choosing differentiated protection. This speaks in favour of unified protection.

3. Identifiability: If the identification of sensitive individuals is difficult or uncertain, then that speaks against differentiated protection. Unified protection has the important advantage of protecting sensitive individuals even if they are not identified.

4. Privacy: In some cases the identification of sensitive groups is problematic from the viewpoint of privacy. The use of biochemical testing for such purposes in a workplace setting is often controversial. ${ }^{57}$ This speaks in favour of unified instead of differentiated protection.

5. The social exclusion caused by differentiated protection: In some cases individuals who receive special protection will be disadvantaged for instance through loss of employment opportunities. If these effects are significant, then that is an argument in favour of unified protection.

6. Previous discrimination: If the persons who will be disadvantaged by negative effects of differentiated protection are already subject to discrimination or otherwise underprivileged, then that is an argument against differentiated protection. As one example of this, in most countries it would be more problematic to weaken the position of black women on the labour market than that of white men.

\section{Application of the criteria}

The distinction between differentiated and unified protection is clearly relevant for pregnancy-related risks. In the above-mentioned examples of existing regulations three variants of differentiated protec- tion are seen: Applied to (1) pregnant women (2) fertile (i.e. potentially pregnant) women, or (3) all women. The reviewed differentiated regulatory strategies did not include male-mediated developmental toxicity. For substances that, according to the best available knowledge only affect the foetus after exposure to the father, protection could be differentiated according to (4) fertile men, or (5) all men. For substances potentially affecting the progeny of both men and women a combination of (2) and (4), i.e. all fertile employees would be a potential alternative. Combining (3) and (5) leads to unified protection. Due to lack of information on male mediated developmental toxicity, we will focus the rest of this discussion on the first three variants of differentiated protection.

The two first criteria likely speak in favour of differentiated protection, although this may vary between exposure agents and/or branches of industry. As shown in previous sections the difference in risk is expected to be large for many chemical substances, as the developing foetus may be harmed at much lower doses than the adult. In addition, the costs of abatement are high for many of these substances, making it economically advategeous to remove the susceptible worker rather than reduce the exposure from the work task.

However, the other four of the six criteria speak generally in favour of a unified rather than a differentiated approach to the protection of pregnant women on the workplace. Most importantly, this applies to the criterion of identifiability. As mentioned above, the most sensitive period is early in a pregnancy when it is often unknown. Due in part to fears of discrimination on the workplace, many women delay announcing a pregnancy to co-workers and superiors as long as possible. ${ }^{58}$ Furthermore, due to storage of hazardous substances in the body, in order to protect the foetus during organogenesis, exposure of the mother will have to be prevented during a period that is different for different substances but will in many cases extend before conception. Obviously,

56 Hansson, 2009, supra note 54.

57 Sven Ove Hansson "Privacy, Discrimination, and Inequality in the Workplace" in Sven Ove Hansson and Elin Palm (eds.) The Ethics of Workplace Privacy (Brussels: Peter Lang., 2005), at pp. 119-135.

58 Danna Greenberg, Jamie Ladge, and Judy Clair "Negotiating Pregnancy at Work: Public and Private Conflicts", 2 Negotiation and Conflict Management Research (2009), pp. 42 et sqq. 
this makes differentiated protection of pregnant women impossible if the pregnancy is unplanned. In a small Swedish survey about $75 \%$ of the pregnant mothers stated that their pregnancies were very or rather well planned, while some $4 \%$ stated that their pregnancies were unplanned. Also, relatively few informants reported actions to reduce risks prior to pregnancy recognition, such as decreasing one's consumption of alcohol or nicotine. ${ }^{59}$ Similar findings were reported from a Danish study. ${ }^{60}$ These studies indicate that a significant number of pregnancies are unplanned, and even when they are planned the parents cannot be expected to have initiated preventive measures prior to pregnancy recognition.

A possible solution to the problem of late pregnancy recognition would be to apply differentiated protection to all fertile female workers or to all female workers. Historically, differences in OELs for lead between women and men have been justified in this way $^{61}$, and so are the mentioned differences in Swedish provisions on medical surveillance of leadexposed workers. However, although this works for some exposures that are potentially dangerous to the foetus, it does not work for substances whose devel-

59 Tydén T, Stern I, Nydahl M, Berglund A, Larsson M, Rosenblad A Aarts C. "Pregnancy planning in Sweden - a pilot study among 270 women attending antenatal clinics", 90 Acta Obstetricia et Gynecologica Scandinavica (2011), pp. 408 et sqq.

60 Mette G. Backhausen, Maria Ekstrand, Tanja Tydén, Britta Kjeldberg Magnussen, Jill Shawe, Jenny Stern, and Hanne K. Hegaard "Pregnancy planning and lifestyle prior to conception and during early pregnancy among Danish women" 19 The European Journal of Contraception and Reproductive Health Care (2014), pp. 57 et sqq.

61 Sven Ove Hansson, Setting the Limit. Occupational Health Standards and the Limits of Science. (New York: Oxford University Press, 1998), at p. 45.

62 Carl G. Heller and Yves Clermont "Spermatogenesis in Man: An Estimate of Its Duration", 140(3563) Science (1963), pp. 184 et sqq.

63 To hold prospective parents, rather than their employers, liable for the possible consequences of prenatal workplace exposures is furthermore a violation of autonomy and bodily integrity rights.

64 Even if a unified protection approach is adopted in future occupational health legislations, there may be benefits in keeping the right to apply for paid leave for pregnancy related reasons. Even though legislation aims at sufficient protection, workplace implementation may be insufficient and pose a risk to the foetus. This has been pointed out previously by for instance Karen Messing in "One-Eyed Science: Scientists, Workplace Reproductive hazards, and the Right to Work" 29 International Journal of Health Services (1999), pp. 155-156.

65 Ibid., at p. 152

66 Michelle R Hebl, Eden B. King, Peter Glick, Sarah L. Singletary, and Stephanie Kazama "Hostile and benevolent reactions toward pregnant women: Complementary interpersonal punishments and rewards that maintain traditional roles", 92 Journal of Applied Psychology (2007), pp. 1499 et sqq. opmental toxicity is mediated through paternal exposure. Since spermatogenesis takes about 64 days $^{62}$, protection of the prospective father would have to extend more than two months before conception. Requiring a planning period for pregnancies is obviously as unrealistic for fathers as for mothers. In summary, differentiated protection is not feasible for substances like solvents or pesticides that may damage the foetus through either maternal or paternal exposure, since the majority of workers on most workplaces are potential future parents.

The privacy criterion also speaks against specific rules for pregnant women. Such rules would demand that women announce the pregnancy at an earlier stage than they might wish to or, for certain exposures, that women announce their intention to attempt to become pregnant. Requiring this as a condition for adequate protection would be a clear and serious infringement on their privacy. ${ }^{63}$ However, differentiated protection of all women (or all women of fertile age) would not seem to infringe on privacy since a person's gender and approximate age are usually known on her workplace.

The social exclusion criterion is at variance with differentiated protection of pregnant women, or of women of fertile age or women in general. Persons who may be in need of costly protection measures, such as additional protective equipment, extended medical surveillance or paid leave run the risk of being disadvantaged in hiring decisions. ${ }^{64}$ Policies intended to protect potential future foetuses have previously resulted and may again result in the exclusion of women from employment opportunities. ${ }^{65}$

Finally, the criterion of previous discrimination speaks in the same direction. Women have an underprivileged position on the labour market and in society in general, and in spite of anti-discrimination laws, pregnant women are still discriminated against in hiring situations when applying for traditionally "male" jobs. This has been shown in social experiments in which women with and without a pregnancy prosthesis posed as job applicants. ${ }^{66}$

\section{Conclusion}

Parents' workplace exposures may have detrimental effects on their progeny. Such effects have been shown for heavy metals, organic solvents, pesticides, and radiation. 
Two major strategies can be used to prevent foetal damage: differentiated protection that reduces exposure only of pregnant workers (or only female workers, or only female workers of fertile age) and unified protection that reduces the exposure of all workers to a level that is sufficiently low to also protect a future or developing foetus. We have seen that the former strategy is applied in several occupational health and safety regulations. Nevertheless, we argue that the differentiated strategy is inefficient in the sense of not providing sufficient protection. This is because it cannot in practice be applied in parts of the period when protection is needed, namely in early pregnancy and (for many substances) prior to conception. Protection of all women would not either be sufficient since preconception exposure of the father for instance to solvents or pesticides has also been shown to give rise to malformations. Furthermore, differentiated protection would aggravate the already prevalent discrimination of women on workplaces and on the labour market.

In summary, unified protection is the only efficient and also the only non-discriminatory regulatory strategy to protect workers' reproductive health. A workplace can only be safe and non-discriminatory if a person can work there without endangering the health of a future child.

Finally it should be recognized that actual workplace conditions do not always satisfy current regulatory requirements. Therefore, even when these requirements do not offer full protection, measures ensuring that they are complied with can significantly reduce risks on the workplace, including risks to the future children of the workers. 